\title{
When in doubt, look to see what works in nature
}

\author{
Frank W. Sellke, MD
}

\footnotetext{
From the Division of Cardiothoracic Surgery, Warren Alpert Medical School of Brown University, Rhode Island Hospital, Providence, RI.

Disclosures: Author has nothing to disclose with regard to commercial support.

Received for publication Sept 3, 2017; accepted for publication Sept 13, 2017; available ahead of print Oct 6, 2017.

Address for reprints: Frank W. Sellke, MD, Division of Cardiothoracic Surgery, Warren Alpert Medical School of Brown University, Rhode Island Hospital, MOC 360, 2 Dudley St, Providence, RI 02905 (E-mail: fsellke@ lifespan.org).

J Thorac Cardiovasc Surg 2018;155:280

$0022-5223 / \$ 36.00$

Copyright $(2017$ by The American Association for Thoracic Surgery

https://doi.org/10.1016/j.jtcvs.2017.09.054
}

In this issue of the Journal, Craig Smith $^{1}$ very nicely describes various adhesives derived from the natural world that may have application to clinical surgery. As he mentions, there are problems with many strong cyanoacrylate-based chemical glues, including toxicity, rigidity, and failure to work on bloody or wet surfaces. They do, however, work. I remember all too well as a new attending surgeon struggling to repair a posterior ventricular perforation despite a very large mound of felt and sutures on the back of the heart. My chief expertly told me to go back on bypass and take all that apart and rearrest the heart. This was necessary to obtain a dry field. He then obtained some "superglue" from his locker that he kept for this specific purpose. We applied the glue to a large piece of felt and slapped it over the defect. It worked like a charm. Now there are commercially available glue patches for repairing ventricular perforations. Having recently used one of these, I can attest that they also work. They are also Food and Drug Administration approved, unlike the previous concoction.

When searching for a solution to a clinical problem, it is often fruitful to look to nature. Since life started on the earth about a billion years after the beginning of this planet, some 4.7 billion years ago, it has evolved to optimize form and function. From organic molecules, viruses and primitive algae formed, which eventually evolved into multicellular organisms such as humans. It is amazing how complex these living systems are. Life has developed cellular products that function very effectively in the environment in which they occur. Baik and colleagues ${ }^{2}$ in their Nature article describe the use of OIAs, or octopus-inspired architectures, that mimic what octopi use to attach to rocks or their next meal. This clearly works in a wet environment because an octopus spends all its time underwater. Smith ${ }^{1}$ describes several other adhesion systems found in nature that have characteristics developed over time that make them well suited to perform the task required.

Looking to nature has relevance not only to biologic glues. The branch of computer science known as artificial good ideas.

\section{References} 396-400.

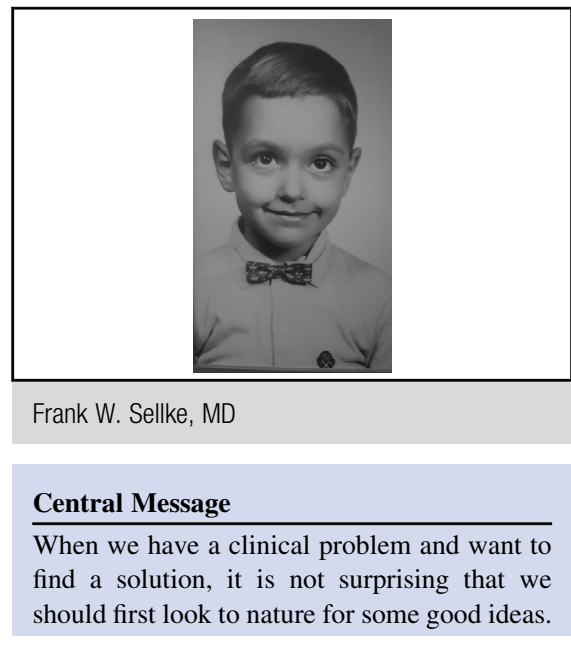

See Article page 278

intelligence uses circuits and algorithms similar to the human brain. This did not occur by accident. After much trial and error, scientists found that it works most efficiently. When performing coronary artery bypass surgery, we sew conduits around the blockages in the arteries. Luckily, we have autologous arteries and veins that the body can do without to provide new sources of perfusion to the ischemic myocardium. There is a reason that we do not use polytetrafluoroethylene, Dacron polyester fabric, or collagen tubes. They do not work. There is intense research going on to replicate the structure and function of natural vessels for use in cardiovascular surgery. These efforts have only led to modest success to date, however, because of the complexities and effectiveness of natural blood vessels compared with the rudimentary properties of artificial vessels. When developing prosthetic heart valves, scientists and engineers try to reproduce the anticalcification processes that nature has developed over eons. Nature has produced, over millions of years, tissues that near perfectly provide the form and function required. It is thus not surprising that if we want to develop a biologic adhesive or other product for treating patients, we should first look to nature for some

1. Smith CR. Tissue adhesive innovations derived from the natural world. J Thorac Cardiovasc Surg. 2018;155:278-9.

2. Baik S, Kim DW, Park Y, Lee TJ, Ho Bhang S, Pang C. A wet-tolerant adhesive patch inspired by protuberances in suction cups of octopi. Nature. 2017;546: 